\title{
Studies on Chitin VII. Preparations of p-Substituted Benzoylchitins
}

\author{
Norio NishI, Hiroyuki OHNUMA, Shin-ichiro NisHIMURA, \\ Oyin SOMORIN,* and Seiichi TOKURA \\ Department of Polymer Science, Faculty of Science, \\ Hokkaido University, \\ Nishi 8-chome, Kita 10-jo, Kita-ku, Sapporo 060, Japan
}

(Received April 28, 1982)

\begin{abstract}
KEY WORDS Chitin/p-Substituted Benzoylchitin/p-Chlorobenzoylchitin / $p$-Methylbenzoylchitin / $p$ - $t$-Butylbenzoylchitin / $p$-Methoxybenzoylchitin / Solubility /
\end{abstract}

Chitin is known to be present very widely and abundantly in nature as an essential supporting structure for several living organisms including fungi, algae, annelids, mollusks, and anthropods. Although chitin is structurally similar to cellulose, it has poor solubility and is more resistant toward chemical reagents because of its strong micelle structure due to inter- or intramolecular hydrogen bonds among hydroxyl and acetamide groups. The poor solubility of chitin and its derivatives in common solvents has been a major drawback to its utilization. For example, cellulose acetate soluble in many organic solvents has many practical uses as fibers, films, paints, and plastics but chitin acetate is practically insoluble in all solvents except acids which tend to decompose it on standing. Chemically modified chitin derivatives with good solubility in organic solvents are highly desirable in order to promote the usefulness of chitin.

It is known that hydrophobic groups have affinity for organic solvents. In our previous investigation, the introduction of a hydrophobic benozyl group onto the chitin molecule was found to enhance its affinity toward organic solvents ${ }^{1}$ as in case of the chemical modification of chitin with aliphatic acyl groups. ${ }^{2-4}$ In the present study, the preparation of the chitin derivatives soluble in many common organic solvents was attempted by chemical modification with various $p$-substituted benzoyl groups.
The preparation of $p$-chlorobenzoylchitins, $p$ methylbenzoylchitins, $p$-t-butylbenzoylchitins and $p$-methoxybenzoylchitins is presented along with solubility properties in this article.

\section{EXPERIMENTAL}

\section{Materials}

Chitin was prepared from Queen Crab shell according to the method of Hackman, ${ }^{5}$ and was powdered to a 45-60 mesh before use. $p$ Chlorobenzoyl chloride, $p$-methylbenzoyl chloride, and methanesulfonic acid were purchased from Wako Pure Chemical Industries, Ltd. $p$ - $t$-Butylbenzoyl chloride and $p$-methoxybenzoyl chloride were purchased from Aldrich Chemical Company, Inc. and Tokyo Kasei Kogyo Co., Ltd., respectively.

\section{p-Substituted Benzoylchitins}

Chitin powder $(1.0 \mathrm{~g})$ was added to methanesulfonic acid $(7 \mathrm{ml})$ with stirring at $5-8^{\circ} \mathrm{C} . p$ Substituted benzoyl chloride ( $p$-chlorobenzoyl, $p$ methylbenzoyl, $p$ - $t$-butylbenzoyl, or $p$-methoxybenzoyl chloride) was added to the solution. The mixture was stirred for $3 \mathrm{hr}$ at $5-8^{\circ} \mathrm{C}$ and then kept at $-20^{\circ} \mathrm{C}$ overnight. The product, precipitated by the addition of cracked ice, was collected by filtration and washed with ice-water.

\footnotetext{
* Present address: Chemistry Department, University of Lagos, Lagos, Nigeria.
} 
The crude products of the $p$-substituted benzoylchitins thus obtained were purified as follows. (a) $p$ Chlorobenzoylchitin: the crude product was suspended in water and the acidic mixture was neutralized with dilute aqueous ammonia to $\mathrm{pH} 7.0$, and boiled for a few minutes to dissolve any mineral salt present. The product was collected by filtration and washed with water. This crude product was suspended in methanol, stirred for $1 \mathrm{~h}$, filtered, washed with methanol and ether, and then dried. (b) $p$-Methylbenzoyl and $p$-t-butylbenzoylchitins: the crude products were suspended in methanol- ether mixture $(1: 10, \mathrm{v} / \mathrm{v})$, and the mixtures were stirred for $1 \mathrm{~h}$. The products were collected by filtration or centrifugation, washed with ether and then dried. (c) $p$-Methoxybenzoylchitin: this product was purified by the same procedures as (b) except ethanol was used instead of the methanolether mixture.

Products with different degrees of substitution were obtained by varying the quantity of $p$ substituted benzoyl chloride added.

Table I. Relationship between the amount of $p$-substituted benzoyl chloride added and the degree of substitution

\begin{tabular}{|c|c|c|c|}
\hline $\begin{array}{l}p \text {-Substituted } \\
\text { group }\end{array}$ & $\frac{\begin{array}{c}\text { Amount of } \\
\text { reagent }\end{array}}{\text { equiv. mol }{ }^{\mathrm{a}}}$ & $\begin{array}{c}\text { Degree of } \\
\text { substitution }^{\mathrm{b}}\end{array}$ & Elemental analysis ${ }^{\mathfrak{c}}$ \\
\hline $\mathrm{Cl}-$ & $\begin{array}{l}1 \\
2 \\
3 \\
4 \\
6\end{array}$ & $\begin{array}{l}0.8 \\
0.9 \\
1.6 \\
1.7 \\
1.8\end{array}$ & $\begin{array}{l}\text { Found: } \mathrm{C}, 53.72 \% ; \mathrm{H}, 3.90 \% ; \mathrm{N}, 2.85 \% \\
\text { Calcd for } 1.7 \text { chlorobenzoylchitin }{ }^{2}: \\
\mathrm{C}, 54.15 \% ; \mathrm{H}, 4.13 \% ; \mathrm{N}, 3.17 \%\end{array}$ \\
\hline $\mathrm{CH}_{3}-$ & $\begin{array}{l}1 \\
2 \\
3 \\
4\end{array}$ & $\begin{array}{l}0.5 \\
0.7 \\
1.0 \\
1.4 \\
\\
\\
1.8\end{array}$ & $\begin{array}{l}\text { Found: } \mathrm{C}, 64.20 \% ; \mathrm{H}, 5.60 \% ; \mathrm{N}, 2.77 \% \\
\text { Calcd for } 1.8 \text { methylbenzoylchitin }{ }^{2} \text { : } \\
\mathrm{C}, 64.40 \% ; \mathrm{H}, 5.74 \% ; \mathrm{N}, 3.35 \%\end{array}$ \\
\hline $\begin{array}{c}\mathrm{CH}_{3} \\
\mathrm{CH}_{3}-\stackrel{\text { C }}{\mathrm{I}}- \\
\stackrel{\mathrm{C}}{\mathrm{H}} \mathrm{H}_{3}\end{array}$ & $\begin{array}{l}1 \\
2 \\
3 \\
4\end{array}$ & $\begin{array}{l}0.6 \\
0.8 \\
1.4 \\
1.4 \\
\\
2.0\end{array}$ & $\begin{array}{l}\text { Found: } \mathrm{C}, 63.01 \% ; \mathrm{H}, 7.01 \% ; \mathrm{N}, 3.11 \% \\
\text { Calcd for } 1.4 \text { butylbenzoylchitin } 2 \text { : } \\
\text { C, } 63.31 \% ; \mathrm{H}, 7.08 \% ; \mathrm{N}, 3.16 \%\end{array}$ \\
\hline $\mathrm{CH}_{3} \mathrm{O}-$ & $\begin{array}{l}1 \\
2 \\
3 \\
4 \\
6\end{array}$ & $\begin{array}{l}0.6 \\
0.6 \\
0.9 \\
\\
1.6 \\
1.6\end{array}$ & $\begin{array}{l}\text { Found: } \mathrm{C}, 54.27 \% ; \mathrm{H}, 5.87 \% ; \mathrm{N}, 3.77 \% \\
\text { Calcd for } 0.9 \text { methoxybenzoylchitin }{ }^{2} \text { : } \\
\mathrm{C}, 54.79 \% ; \mathrm{H}, 5.83 \% ; \mathrm{N}, 4.21 \%\end{array}$ \\
\hline
\end{tabular}

a Equivalent moles of $p$-substituted benzoyl chloride per mol of $N$-acetylglucosamine residue.

b $p$-Substituted benzoyl groups for each $N$-acetylglucosamine residue.

c The degree of substitution of four samples was determined by elemental analysis, and that for the other samples was determined according to the method of Ando and Kataoka. ${ }^{6}$ 


\section{Estimation of the Degree of Substitution}

The degree of substitution for one sample of each derivative was determined by elemental analysis with a Yanagimoto CHN Corder, Model MT-2 for standardization. The degree of substitution for the other samples was estimated using the method of Ando and Kataoka, ${ }^{6}$ which was successfully employed to determine the degree of acetylation of acetylchitins, with a JASCO A-302 Infrared Spectrophotometer by a comparison with the results of the above standard samples.

\section{RESULTS AND DISCUSSION}

Recently, we reported an effective method for the acylation of chitin, using the acyl chloride- or acyl anhydride-methanesulfonic acid system. ${ }^{1-4}$ Methanesulfonic acid was found to be a suitable solvent for chitin as well as a good acidic catalyst for acylation reactions. The decomposition of the chitin molecule during the reactions was considered to be slight as long as the reaction temperature was low, as reported previously, ${ }^{3}$ since many kinds of acylchitins such as acetylchitins, ${ }^{2}$ propionylchitins, ${ }^{3}$ butyrylchitins ${ }^{3}$ and hexanoylchitins ${ }^{4}$ could be prepared by this method without significant decomposition of the chitin molecule. Benzoylchitins with various degrees of benzoylation could also be prepared successfully, ${ }^{1}$ although a large excess of benzoyl chloride was needed in this case. Hence, $p$ substituted benzoylations were carried out by similar procedures, employing the corresponding acyl chloride-methanesulfonic acid systems. Each reaction was carried out with different amounts of reagents to give $p$-substituted benzoylchitins with different degrees of substitution. The relationship between the amount of reagent added and the degree of substitution is shown in Table I. The degree of substitution increased with the quantity of reagent added, and products with high degrees of

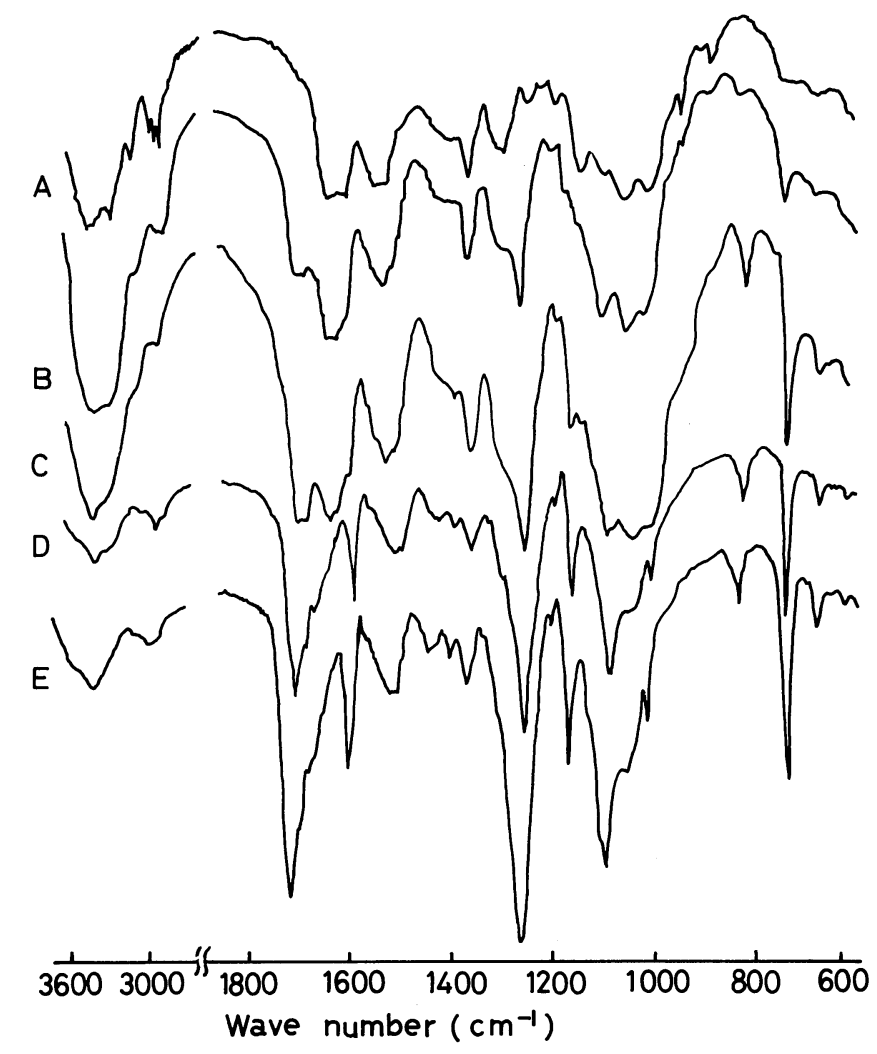

Figure 1. Infrared absorption spectra of chitin (A) and $p$-methylbenzoylchitins $(\mathrm{B}, 0.5 ; \mathrm{C}, 0.7 ; \mathrm{D}, 1.4 ; \mathrm{E}$, 1.8 p-methylbenzoylchitin). 
substitution were obtained when $4-6 \mathrm{~mol}$ of reagent to $1 \mathrm{~mol}$ of $\mathrm{N}$-acetylglucosamine residue were employed. The necessary amounts of reagents to obtain products of high degree of substitution were thus less than in case of the benzoylation reaction, ${ }^{1}$ in which $c a$. 10 equiv. mol of benzoyl chloride were used. This may possibly reflect the effect of $p$ substituted groups on the reactivity of the reagents or their solubility in methanesulfonic acid.

The infrared absorption spectra of $p$ methylbenzoylchitins with various degrees of substitution are shown in Figure 1. These spectra show that an increase in the degree of methylbenzoylation corresponds to a decrease in absorption at around $3400 \mathrm{~cm}^{-1}$ which is due to the hydroxyl groups, and to the appearance of new absorption frequencies at 1720 and $1280 \mathrm{~cm}^{-1}$ which are characteristic of the benzoyl ester. Absorptions characteristic of the benzene ring also appear at 1610,840, 750 and 690 $\mathrm{cm}^{-1}$. The IR spectra for $p$-chlorobenzoylchitin, $p$ - $t$-butylbenzoylchitin, and $p$-methoxybenzoylchitin are also similar to those of $p$-methylbenzoylchitin, as evident from Figure 2.

Among the four kinds of the $p$-substituted benzoylchitins, the solubility properties of $p$ chlorobenzoylchitins are not significantly better than those of chitin, and rather less than those of previously reported benzoylchitins. These chitins, even in the case of samples with high degrees of substitution, are soluble only in acidic solvents such as formic or dichloroacetic acid, and are not soluble in common organic solvents. On the other hand, $p$ methylbenzoylchitins have strikingly good solubility properties in many organic solvents. They are easily soluble in alcohols (methanol, ethanol, 1butanol, and benzyl alcohol), halogenated hydrocarbons (dichloromethane, dichloroethane, tetrachloroethane, and chloroform), and other common organic solvents (DMF, DMA and tetrahydrofuran) in addition to the acidic solvents including

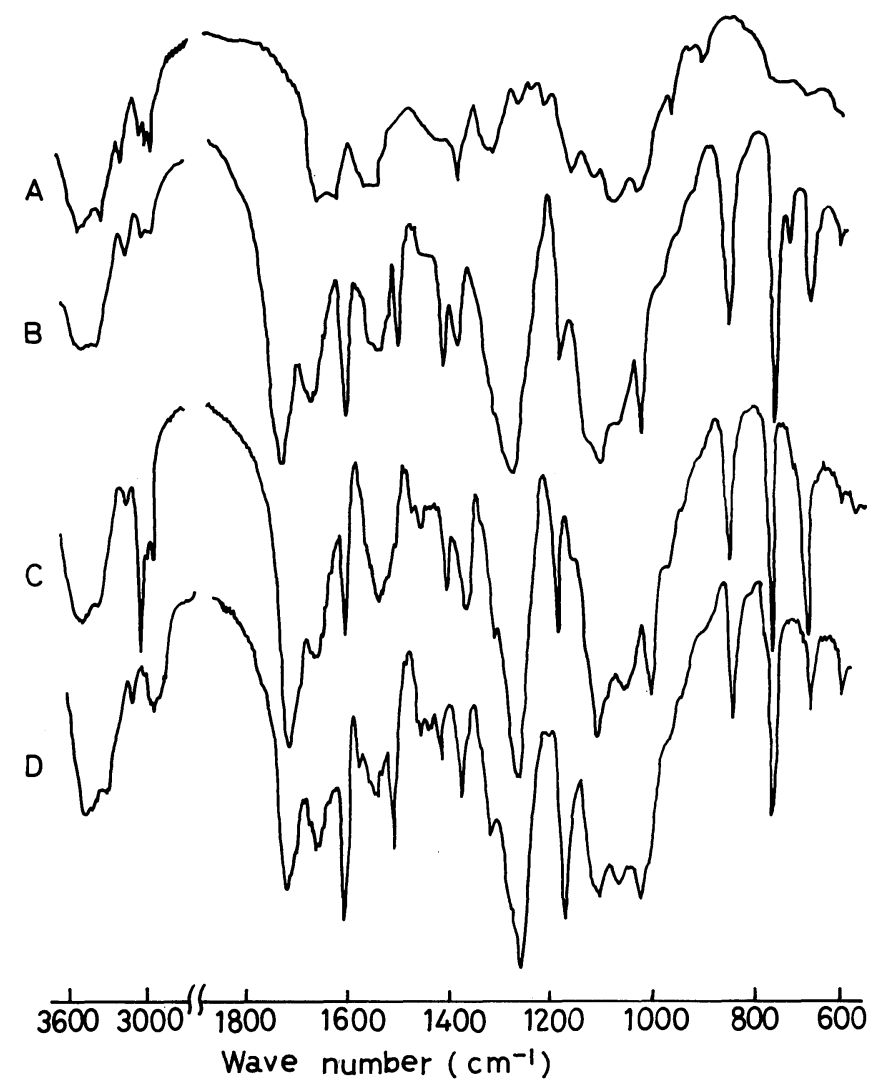

Figure 2. Infrared absorption spectra of A, chitin; B, $1.7 p$-chlorobenzoylchitin; C, $1.4 p$ - $t$-butylbenzoylchitin; D, 0.9 p-methoxybenzoylchitin. 
formic, dichloroacetic and glacial acetic acid. $p$ - $t$ Butylbenzoylchitins also showed very good solubility properties, although not as much as $p$-methylbenzoylchitins. The solubilities of $p$-methoxybenzoylchitins are intermediate between those of $p$ - $t$-butylbenzoylchitins and $p$-chlorobenzoylchitins. Arranged in the order of their solubility, these compounds may be listed as follows: chitin $<p$-chlorobenzoylchitin $<$ benzoylchitin $<p$-methoxybenzoylchitin $<p$ - $t$-butylbenzoylchitin $<p$-methylbenzoylchitin.

Thus some $p$-substituted benzoylations such as $p$ methylbenzoylation or $p$ - $t$-butylbenzoylation were found to bring about great enhancement in the solubility properties of chitin. This increase in solubility in many common organic solvents will pro- mote the usefulness of chitin and widen the scope of its industrial application.

\section{REFERENCES}

1. O. Somorin, N. Nishi, S. Tokura, and J. Noguchi, Polym. J., 11, 391 (1979).

2. N. Nishi, J. Noguchi, S. Tokura, and H. Shiota, Polym. J., 11, 27 (1979).

3. K. Kaifu, N. Nishi, T. Komai, S. Tokura, and O. Somorin, Polym. J., 13, 241 (1981).

4. K. Kaifu, N. Nishi, and T. Komai, J. Polym. Sci., Polym. Chem. Ed., 19, 2361 (1981).

5. R. H. Hackman, Austr. J. Biol. Sci., 7, 168 (1958).

6. T. Ando and S. Kataoka, Kobunshi Ronbunshu, 37, 1 (1980). 